\title{
Existence and Uniqueness for Optimal Dividend and Issuance of Equity Policies in The Presence of Interest \\ Memory Mandiudza*
}

Department of Mathematics and Computer Science, Great Zimbabwe University, P.O. Box 1235, Masvingo, Zimbabwe

DOI: $10.36347 /$ sipms.2020.v07i09.004

| Received: 09.09.2020 | Accepted: 17.09.2020 | Published: 30.09.2020

*Corresponding author: Memory Mandiudza

Abstract

Qualitative properties of the solutions for the stochastic differential equation such as existence and uniqueness under Lipschitz condition and linear growth conditions are formulated and proved. The solutions attained are continuous adapted stochastic processes.

Keywords: Optimal Dividend, Hamilton-Jacobi-Bellman Equation and Lipschitz condition.

Copyright @ 2020: This is an open-access article distributed under the terms of the Creative Commons Attribution license which permits unrestricted use, distribution, and reproduction in any medium for non-commercial use (NonCommercial, or CC-BY-NC) provided the original author and source are credited.

\section{INTRODUCTION}

The settlement of dividend in a financial sector is one of the central resolutions of a corporate business organization. Dividends are commonly defined as the amount of money paid routinely which can be yearly by a business organisation to its shareholders from its profits or reserves. A classical problem in the discipline of financial mathematics is to maximize the cumulative anticipated discounted dividend pay-outs. Scholars like Borch [3] and Gerber [5] made a seminal contribution on optimization of dividend payouts. Gerber [5] established the existence of an optimal dividend payment strategy and revealed that it had a band structure. Azcue and Muler in 2010 examined an optimal dividend problem for an insurance company whose unrestricted reserve process unfolded as a classical Cramér-Lundberg process. Their main target was to obtain a strategy that incorporates both investment and dividend payment policies.

Dividend and issuance of new equity model for a corporation that controlled risk exposure was examined by Sethi and Taksar [7] and Lokka and Zervos [12] are some of the professionals who scrutinised the optimal dividend control problem with the likelihood of bankruptcy. Of late Mandiudza, Chikodza and Mwareya (2018) examined the optimal dividend and issuance control problem of the insurance company in the presence of transaction costs and interest. In spite of voluminous publications on matters with respect to diffusion models for companies that can control their risk exposure by payment of dividend, very few papers included the interest rate component as in Mandiuza et al. [6]. The author therefore seeks to prove the existence and uniqueness of the solution attained in Mandiudza et al. [6] paper.

The existence and uniqueness of solution are included in the most fundamental and vital concepts in qualitative theory of stochastic differential equations (SDEs). Over the past two decades, the existence and uniqueness of solution for SDEs have been examined in numerous publications see [4, 12, 13]. Taniguchi [10], Bao and Hou [2], and Taniguchi [11] have deliberated on the existence and uniqueness of solutions to SDEs under the non-Lipschitzian condition. In this paper existence and uniqueness of optimal dividend and issuance of equity policies in the presence of interest problem under Lipschitz condition and linear growth conditions are formulated and proved.

The rest of this paper is organized as follows. In Section 2, some relating notations and preliminary facts are introduced. Section 3 obtains the existence and uniqueness of solution for a class of SDEs with linear growth condition. In Section 4, the conclusion is given.

\section{PRELIMINARIES}

This section is covered with some notations and preliminary results which are used in subsequent sections. In this paper, we appropriate the symbols as follow: $\mathbb{R}^{n}$ denotes the usual $n$-dimensional Euclidean space, $\|$.$\| denotes norm in \mathbb{R}^{n}$. Let $\left(\Omega, F, F_{t}, P\right)$ be a filtered probability space satisfying the usual conditions and carrying a standard, one dimensional, $F_{t}$-Brownian motion $\left\{W_{t}\right\}_{t}$. Suppose that the reserves $X_{t}$, at time $t$, of 
the firm, earn interest at a constant rate $\rho$. Given a dividend process $L_{t}$ and an issuance of equity process $G_{t}$, the evolution of liquid reserves of the company is

$$
\mathrm{dX}_{\mathrm{t}}=(\mu+\rho) \mathrm{X}_{\mathrm{t}}+\sigma \mathrm{dW}_{\mathrm{t}}-\mathrm{d} L_{\mathrm{t}}+\mathrm{dG}_{\mathrm{t}}, \mathrm{X}_{0}=x
$$

Where $x \geq 0$ represents the reserves at time zero, $\mu$ and $\sigma$ are parameters describing the growth rate and the volatility of the reserves process respectively. modelled by following the stochastic differential equation

\section{Existence and Uniqueness Theorem}

In this section, we present a concrete situation in which the results from the preceding section are relevant. The next result is concerned with showing that the HJB equation above has a unique solution.

Theorem 3.1 Let us assume that there exists $C>0$ such that

$$
\|(\mu+\rho x)(x)-(\mu+\rho x)(y)\|+\|\sigma(x)-\sigma(y)\| \leq C\|x-y\| ; x, y \in \mathbb{R}^{n} .
$$

Then for every $\mathrm{x}_{0} \in \mathbb{R}^{n}$, there exists a unique continuous and adapted process $\left(X_{t}\right)_{t \geq 0}$ such that for $\mathrm{t} \geq 0$.

$$
\mathrm{X}_{\mathrm{t}}=\mathrm{X}_{0} \mathrm{e}^{\mathrm{pt}}+\frac{\mu}{\mathrm{p}}\left(1-\mathrm{e}^{\mathrm{pt}}\right)+\sigma \int_{0}^{t} e^{\mathrm{p}(\mathrm{t}-\mathrm{s})} \mathrm{dWs}-\int_{0}^{t} e^{\mathrm{p}(\mathrm{t}-\mathrm{s})} \mathrm{dLs}+\int_{0}^{t} e^{\mathrm{p}(\mathrm{t}-\mathrm{s})} \mathrm{dGs}
$$

Moreover for every $\mathrm{T} \geq 0$,

$$
\mathrm{E}\left(\sup _{0 \leq \mathrm{s} \leq \mathrm{T}}\left|\mathrm{X}_{\mathrm{s}}\right|^{2}\right)<+\infty \text {. }
$$

Proof of Existence of solutions is proved by a variant of Picard's method of successive approximations. Let an initial value be $\mathrm{x}$, and define a sequence of adapted process $\mathrm{X}_{\mathrm{k}}(\mathrm{t})$ by

$$
\begin{aligned}
& \mathrm{X}_{0}(\mathrm{t})=\mathrm{X}_{0} \text { for } \mathrm{t} \geq 0 \text { and define successively, for } \mathrm{k} \geq 1 \\
& \left.\left.\mathrm{X}_{\mathrm{k}}(\mathrm{t})=\mathrm{X}_{0} \mathrm{e}^{\mathrm{pt}}+\int_{0}^{t}(\mu+\rho \mathrm{x}) \mathrm{X}_{\mathrm{k}-1}(\mathrm{t}), \mathrm{s}\right) \mathrm{e}^{\mathrm{ps}} \mathrm{ds}+\int_{0}^{t} \sigma\left(\mathrm{X}_{\mathrm{k}-1}(\mathrm{t}), \mathrm{s}\right), \mathrm{s}\right) \mathrm{e}^{\mathrm{p}(\mathrm{t}-\mathrm{s})} \mathrm{dWs}+\int_{0}^{t}\left(\mathrm{X}_{\mathrm{k}-1}(\mathrm{t}), \mathrm{s}\right) \mathrm{e}^{\mathrm{p}(\mathrm{t}-\mathrm{s})} \mathrm{dLs} \\
& +\int_{0}^{t}\left(\mathrm{X}_{\mathrm{k}-1}(\mathrm{t}), \mathrm{s}\right) \mathrm{e}^{\mathrm{p}(\mathrm{t}-\mathrm{s})} \mathrm{dGs} \text {, for } \mathrm{n}=0,1,2 \ldots
\end{aligned}
$$

By induction, the process $\mathrm{X}_{\mathrm{k}}(\mathrm{t})$ are welldefined and have continuous paths. The problem is to show that these converge uniformly on compact time intervals, and that the limit process is a solution to the stochastic differential equation.

First we will show that for each $t \geq 0$ the sequence of random variables $\mathrm{X}_{\mathrm{k}}(\mathrm{t})$ converges in $\mathrm{L}^{2}$ to a random variable $X(t)$, necessarily in $L^{2}$. The first two terms of the sequence are $\mathrm{X}_{0}(\mathrm{t}) \equiv \mathrm{X}$ and for both of these the random variables $X_{j}$ are uniformly bounded in $L^{2}$ for $\mathrm{t}$.
Remark 3.2. Iterations are well defined. They generate progressively measurable almost surely continuous functions at each stage and by induction they are well defined.

In order to prove the convergence of the iteration scheme we estimate successive differences. Let us assume without loss of generality that $\mathrm{s}_{0}=0$ and pick a time $[0, \mathrm{~T}]$ in which we will prove convergence. If we denote the difference

$$
\begin{aligned}
& X_{k}(t)-X_{k-1}(t) \text { by } \eta_{k}(t), \text { we have } \\
& \left.\eta_{k+1}(t)=\int_{0}^{t}\left[\sigma\left(X_{k}(t), s\right)-\sigma\left(X_{k-1}(t), s\right)\right] d W s+\int_{0}^{t}\left[(\mu+\rho x) X_{k}(t), s\right)-(\mu+\rho x)\left(X_{k-1}(t), s\right)\right] d s \\
& =\int_{0}^{t} \delta_{k}(s) d w(s)+\int_{0}^{t} \delta_{k}(s) d s .
\end{aligned}
$$

By Lipschitz assumption

$$
\left\|\delta_{\mathrm{k}}(\mathrm{s})\right\| \leq \mathrm{A}\left\|\eta_{\mathrm{k}}(\mathrm{s})\right\| \text { and }\left\|\mathrm{Q}_{\mathrm{k}}(\mathrm{s})\right\| \leq \mathrm{A}\left\|\eta_{\mathrm{k}}(\mathrm{s})\right\| .
$$

We can estimate

$$
\sup _{0 \leq \tau \leq t}\left\|\eta_{\mathrm{k}}(\tau)\right\| \leq \sup _{0 \leq \tau \leq t}\left\|\int_{0}^{t} \delta_{\mathrm{k}}(\mathrm{s}) \mathrm{dw}(\mathrm{s})\right\|+\int_{0}^{t}\left\|\varrho_{\mathrm{k}}(\mathrm{s})\right\| \mathrm{ds} \text {. }
$$

By Doob's inequality for martingales,

$$
\begin{aligned}
& \mathrm{E}\left[\sup _{0 \leq \tau \leq \mathrm{t}}\left\|\int_{0}^{t} \delta_{\mathrm{k}}(\mathrm{s}) \mathrm{dw}(\mathrm{s})\right\|^{2} \leq \mathrm{C}_{0} \mathrm{E}\left\|\int_{0}^{t} \delta_{\mathrm{k}}(\mathrm{s}) \mathrm{dw}(\mathrm{s})\right\|^{2}=\mathrm{C}_{1} \int_{0}^{t} E\left[\left\|\delta_{\mathrm{k}}(\mathrm{s})\right\|^{2}\right] \mathrm{d}(\mathrm{s}),\right. \\
& \leq \mathrm{A}^{2} \mathrm{C}_{1} \int_{0}^{t} E\left[\left\|\eta_{\mathrm{k}}(\mathrm{s})\right\|^{2}\right] \mathrm{d}(\mathrm{s}) .
\end{aligned}
$$

On the other hand we can estimate for $\mathrm{t} \leq \mathrm{T}$.

$$
\mathrm{E}\left[\int_{0}^{t}\left\|\varrho_{\mathrm{k}}(\mathrm{s})\right\|^{2} \mathrm{~d}(\mathrm{~s})\right] \leq \mathrm{TE}\left[\int_{0}^{t}\left\|\varrho_{\mathrm{k}}(\mathrm{s})\right\|^{2} \mathrm{~d}(\mathrm{~s})\right] \leq \mathrm{A}^{2} \mathrm{~T}\left[\int_{0}^{t} \mathrm{E}\left\|\varrho_{\mathrm{k}}(\mathrm{s})\right\|^{2}\right] \mathrm{d}(\mathrm{s}) .
$$


Putting the two pieces together, if we denote by

$$
\Delta_{\mathrm{k}}(\mathrm{t})=\mathrm{E}\left[\sup _{0 \leq \tau \leq \mathrm{t}}\left\|\eta_{\mathrm{k}}(\tau)\right\|^{2}\right]
$$

Then, with $\mathrm{C}_{\mathrm{T}}=\mathrm{A}^{2} \mathrm{C}_{1}(1+\mathrm{T})$,

$$
\Delta_{\mathrm{k}}(\mathrm{t}) \leq \mathrm{C}_{\mathrm{T}} \int_{0}^{t} \Delta_{\mathrm{k}-1}(\mathrm{~s}) \mathrm{ds} .
$$

Clearly

$$
\eta_{1}(\mathrm{t})=\int_{s 0}^{t} \delta\left(\mathrm{X}_{0}, \mathrm{~s}\right) \mathrm{dW}(\mathrm{s})+\int_{0}^{t}(\mu+\rho \mathrm{x})\left(\mathrm{X}_{0}, \mathrm{~s}\right) \mathrm{ds}
$$

and

$$
\Delta_{1}(\mathrm{t}) \leq \mathrm{C}_{\mathrm{T}} \mathrm{t}
$$

By induction

$$
\Delta_{\mathrm{k}}(\mathrm{t}) \leq \frac{C_{T}{ }^{k} t^{t}}{k !}
$$

From the convergence of $\sum_{k}\left[\frac{C_{T} t^{t}}{k !}\right]^{1 / 2}$ we concluded that $\sum_{k} E\left[\sup _{0 \leq \tau \leq t}\left\|\eta_{\mathrm{k}}(\tau)\right\|\right]<\infty$.

By Fubin's theorem

$$
\sum_{k} E \sup _{0 \leq \tau \leq t}\left\|\eta_{\mathrm{k}}(\tau)\right\|<\infty \text { a.e. } \mathrm{P} \text {. }
$$

In other words for almost all $\omega$ with respect to $\mathrm{P}$,

$$
\lim _{n \rightarrow \infty} \eta_{k}(t)=X(t)
$$

Exists uniformly in any finite time interval [0, $\mathrm{T}$. The limit $\mathrm{X}(\mathrm{t})$ is easily seen to be progressively measurable solution of equation (2.0). Uniqueness is a slight variation of the same method. If there are two solutions $X(t)$ and $X^{\prime}(t)$ their difference $\eta(t)$ satisfies

$$
\eta(\mathrm{t})=\int_{0}^{t}\left[\sigma(\mathrm{X}(\mathrm{t}), \mathrm{s})-\sigma\left(\mathrm{X}^{\prime}(\mathrm{t}), \mathrm{s}\right)\right] \mathrm{dWs}+\int_{0}^{t}[(\mu+
$$
$\left.\rho \mathrm{x}) \mathrm{X}(\mathrm{s}), \mathrm{s})-(\mu+\rho \mathrm{x})\left(\mathrm{X}^{\prime}(\mathrm{s}), \mathrm{s}\right)\right] \mathrm{ds}$

$$
=\int_{0}^{t} \delta(\mathrm{s}) \mathrm{dw}(\mathrm{s})+\int_{0}^{t} \mathrm{Q}(\mathrm{s}) \mathrm{ds}
$$

With

$\|\delta(\mathrm{s})\| \leq \mathrm{A}\|\eta(\mathrm{s})\|$ and $\|\varrho(\mathrm{s})\| \leq \mathrm{A}\|\eta(\mathrm{s})\|$. Just as in the proof of convergence, for the quantity

$$
\Delta(\mathrm{t})=\mathrm{E}\left[\sup _{0 \leq \tau \leq t}\left\|\eta_{\mathrm{k}}(\tau)\right\|^{2}\right] .
$$

We can now obtain

$$
\Delta(\mathrm{t}) \leq \mathrm{C}_{\mathrm{T}} \int_{0}^{t} \Delta(\mathrm{s}) \mathrm{ds} .
$$

We have the obvious estimate $\Delta(\mathrm{t}) \leq \mathrm{C}_{\mathrm{T}}$ and we obtain by iteration

$$
\Delta(\mathrm{t}) \leq \mathrm{C}_{\mathrm{T}}{ }^{\mathrm{k}+1} \frac{t^{t}}{k !} \text { for every } \mathrm{k} .
$$

Therefore $\Delta(\mathrm{t}) \equiv 0$ implying uniqueness.

\section{CONCLUSION}

This paper considers the problems of existence and uniqueness of solution for a class of stochastic differential equations with interest rate component, which satisfies linear growth condition. Some new criteria ensuring the existence and uniqueness of solution with an interest rate component were presented.

\section{REFERENCES}

1. Løkka, A., \& Zervos, M. (2008). Optimal dividend and issuance of equity policies in the presence of proportional costs. Insurance: Mathematics and Economics, 42(3), 954-961.

2. Bao, J., \& Hou, Z. (2010). Existence of mild solutions to stochastic neutral partial functional differential equations with non-Lipschitz coefficients. Computers \& Mathematics with Applications, 59(1), 207-214.

3. Borch, K. (1974). The Mathematical Theory of Insurance. Lexington Books, D.C. Heath and Co., Lexington, $M A$.

4. Fan, Z., Liu, M., \& Cao, W. (2007). Existence and uniqueness of the solutions and convergence of semi-implicit Euler methods for stochastic pantograph equations. Journal of Mathematical Analysis and Applications, 325(2), 1142-1159.

5. Gerber, H. U. (1972). Games of economic survival with discrete-and continuous-income processes. Operations research, 20(1), 37-45.

6. Mandiudza, M., Chikodza, E., \& Mwareya, N. (2018). Optimal Dividend and Issuance of Equity Policies in the Presence of Interest. Journal of Mathematical Finance, 8(2), 302-316.

7. Sethi, S. P., \& Taksar, M. I. (2002). Optimal financing of a corporation subject to random returns. Mathematical Finance, 12(2), 155-172.

8. Schurz, H. (2007). Existence and uniqueness of solutions of semilinear stochastic infinitedimensional differential systems with H-regular noise. Journal of mathematical analysis and applications, 332(1), 334-345.

9. Taniguchi, T. (2011). The existence of energy solutions to 2-dimensional non-Lipschitz stochastic Navier-Stokes equations in unbounded domains. Journal of Differential Equations, 251(12), 3329-3362.

10. Taniguchi, T. (2009). The existence and uniqueness of energy solutions to local non-Lipschitz stochastic evolution equations. Journal of mathematical analysis and applications, 360(1), 245-253.

11. Wei, F., \& Wang, K. (2007). The existence and uniqueness of the solution for stochastic functional differential equations with infinite delay. Journal of Mathematical Analysis and Applications, 331(1), 516-531.

12. $\mathrm{Xu}, \mathrm{Y} ., \& \mathrm{Hu}, \mathrm{S}$. (2010). The existence and uniqueness of the solution for neutral stochastic functional differential equations with infinite delay in abstract space. Acta applicandae mathematicae, 110(2), 627-638. 